\title{
MODELLING THE EVOLUTION OF THE FINANCIAL IMPACTS OF FLOOD AND STORM SURGE BETWEEN 2015 AND 2050 IN FRANCE
}

\author{
DAVID MONCOULON ${ }^{1}$, MARTINE VEYSSEIRE ${ }^{2}$, JEAN-PHILIPPE NAULIN ${ }^{1}$, ZI-XIANG WANG $^{1}$, \\ PIERRE TINARD ${ }^{1}$, JÉRÉMY DESARTHE ${ }^{1}$, CHADI HAJJI $^{1}$, THOMAS ONFROY $^{1}$, \\ FABIENNE REGIMBEAU ${ }^{2}, \&$ MICHEL DÉQUÉ ${ }^{2}$ \\ ${ }^{1}$ Caisse Centrale de Réassurance, PARIS, France \\ ${ }^{2}$ Météo France, TOULOUSE CEDEX 1
}

\begin{abstract}
CCR (Caisse Centrale de Réassurance) is a French reinsurance company playing a major role in the natural catastrophe coverage in France. Since 2003, CCR has been developing tools for the estimation of its exposure to climatic risks. These tools cover three main perils: flood, storm surge and drought. Models are used to estimate the insurance losses and are systematically used for all major climatic events. Both modelling calibration and validation are based on an important policy and claim database. It was created in 2003 and supplied every year with insurer's data. In order to evaluate the financial exposure for insurance of extreme events, a stochastic approach has been developed since 2011, for flood, storm surge and drought. The simulation of the stochastic event set allows us to estimate the mean annual losses and losses associated with different return periods. The objective of this approach is to connect the impact models for all perils with a large set of climate simulations. ARPEGE-Climate (Météo-France) is a model that is used to generate two sets of 200 years of hourly atmospheric time series: at current conditions and at year 2050 conditions according to RCP (Representative Concentration Pathways) 4.5. The main climate data used are: hourly rainfall, wind speed and atmospheric pressure and the Soil Wetness Index that is issued from a complementary surface model. The hazard and vulnerability models developed are based on the climatic data to compute continuous loss estimations. The method proposed will take into consideration development scenarios to evaluate the consequences of demographic growth and insured values evolution. The simulations show a global loss increase in 2050 which can be attributed to climatic factors such as extreme rainfall increase or sea level rise as well as, for a major part, the population and insured value growth in areas at risk.

Keywords: climate change, flood, insurance losses, storm surge, vulnerability.
\end{abstract}

\section{INTRODUCTION}

Even if the year 2015 has been relatively quiet in terms of economic losses due to natural catastrophes [1], the financial impact of natural disasters in the world continuously increases since 50 years [2]. The causes of this global increase in the last decades can be explained by the following factors: the world population continuous growth in the cities (concentration of vulnerability in small areas); economic growth in emerging countries and the possible rise of frequency and intensity of extreme events due to climate change.

If the International Panel on Climate Change report [3] gives a clear vision of the anthropogenic causes of climate change, the conclusions in terms of impacts over the water cycle are more balanced as climate change effects will not be uniform, but different 
from a region to another. Several studies have shown that extreme rainfall could be more frequent at the mid latitude, inducing an increasing of the frequency and intensity of catastrophic events [4,5]. Sea-level rise effect will also increase the exposure of coastal regions to storm surge [6].

In France, the insured losses due to climatic disasters are covered by the Natural Catastrophes (Nat Cat) scheme (for flood, droughts, cyclonic winds) or by traditional insurance (for windstorm, hail, snowfall). CCR (Caisse Centrale de Réassurance) is a public reinsurer providing the unlimited state-guarantee to its clients for natural disaster coverage. In this purpose, CCR has developed models to evaluate insurance damages caused by climatic events such has flood [7], drought and storm surge [8].

In order to assess the financial impacts of climate change for natural disaster insured losses in France, these models have been combined with climatic projections generated by the ARPEGE-Climate model, developed by Météo-France [9]. The aim of this multi-peril approach, focusing on flood and storm surge in this paper, is to simulate 200 fictive years corresponding to the actual and the 2050 climatic conditions, and to estimate the insured losses resulting. As the insurance exposure is a key component of the damage estimation, a first evaluation of the possible evolution of the vulnerability has been made.

\section{DATA AND METHODOLOGY}

\subsection{Climatic model}

The modelling system developed for estimating the potential impacts of climate change by 2050 is based on the use of Météo-France climate simulations for supplying hazard and damage models developed by CCR.

As part of Intergovernmental Panel on Climate Change activities (IPCC), Météo-France has implemented its global ARPEGE-Climate model (Action de Recherche Petite Echelle Grande Echelle) for each of the trajectories of variation in greenhouse gas concentrations (RCP: Representative Concentration Pathways) to produce simulations up to 2100 for the whole world.

ARPEGE-Climate [9] is the atmospheric model used by Météo-France to perform the Coupled Model Intercomparison Project (CMIP) inter-comparison exercises [10]. This is a global spectral atmospheric model derived from the ARPEGE/IFS (Integrated Forecast System) numerical weather prediction model developed jointly by Météo-France and European Centre for Medium range Weather Forecast. ARPEGE-Climate, even if global, relies on a stretched grid that provides output at finer resolution over an area of interest.

For CCR's needs, Météo-France configured ARPEGE-Climate (version 6) to refine calculations in the region of interest, continental France. Two simulations of 200 years, one at the current climate (2000) and the other at a future climate (2050), have been performed in a configuration with 31 vertical levels and a resolution of about $20 \mathrm{~km}$ over Europe and $250 \mathrm{~km}$ on the opposite ends of the earth. The model includes the soil-vegetation-atmosphere transfer scheme SURFEX (Surface Externalisée) [11]. Fields from the model are stored every hour.

Both simulations are forcing experiments with stationary greenhouse gases concentration throughout the 200 years. The forcing sea surface temperatures are long monthly time-series from CMIP experiments. The astronomic parameters are from the year 2001 to 2200, so the chronologic series are dated but the simulated data are not prediction, but realistic fictitious atmospheric conditions. 
The hypothesis chosen for simulation of the 2050 future climate is RCP 4.5 (solar radiation forcing of $+4.5 \mathrm{~W} / \mathrm{m} 2$ in 2100) which follows a progression that stabilises without excess by 2100 , with a rate of $660 \mathrm{ppm} \mathrm{CO}_{2}$ equivalent, which corresponds to a mean increase of $1.8^{\circ} \mathrm{C}$ in 2100 in relation to the present mean temperature. This variation scenario is a bit over the objectives targeted during COP 21 in Paris.

\subsection{Hazard and insurance-damage models}

\subsubsection{Flood model}

The flood model developed by CCR [7] is made up of two complementary models. The first is the surface run-off model. On the basis of the rainfall measurements obtained from the ARPEGE-Climate simulations, it calculates the water volumes that flow on the surface and under the surface of the ground. This run-off model takes into account topography, but also land use to reproduce the behaviour of impervious areas.

The river overflow model is used to estimate the flow rate of the main water courses and their overflow during an extreme event. This overflow is based on the spread of water on a digital model of ground, describing the topography of the impacted area. These two models are complementary and each has their own importance, since the CCR's loss experience data have shown that a large proportion of damage to property - up to 50\% [7] - is not located in the overflow area of the main water courses, but perhaps caused by secondary water courses or by surface run-off.

\subsubsection{Coastal flooding model}

Severe weather events create meteorological conditions that drive up the sea water level, creating a storm surge. This storm surge could result in coastal flooding if it occurs during high tides.

The modelling system developed by CCR [8] is based on the combination of three models. The first is the TELEMAC-2D hydrodynamic model [12] which is used to simulate the tide and the rise in sea level caused by a weather event. It uses wind speed and atmospheric pressure data obtained from the ARPEGE-Climate model. Waves, which may contribute considerably to coastal flooding, are simulated with the TOMAWAC model [13], supplied by outputs from the TELEMAC-2D model. Lastly, the seawater levels resulting from the tide, the storm surge and the breaking of waves are propagated on land by a flooding model, similar to LISFLOOD-FP [14]. Wave overtopping phenomenon is not modelled in this approach.

In addition to the variation in climate, the warming and induced dilatation of seas and the melting of polar ice caps could have a direct effect on sea level. According to the IPCC simulations based on RCP 4.5; this could rise by as much as $20 \mathrm{~cm}$ by 2050 in relation to the mean sea level in 2015. In order to measure the impact of this rise, simulations of events with the 2050 climate were modified by increasing the sea level by $20 \mathrm{~cm}$. In this study, the study of storm surge only concerns the Atlantic coastline which was considered as a priority due to a strongest exposure to the rise of water levels than Mediterranean coastline.

\subsubsection{Damage simulation}

Continental and coastal flood hazard maps modelled for individual events are crossed with a vulnerability database. This database describes insurance risks in terms of insured values and 

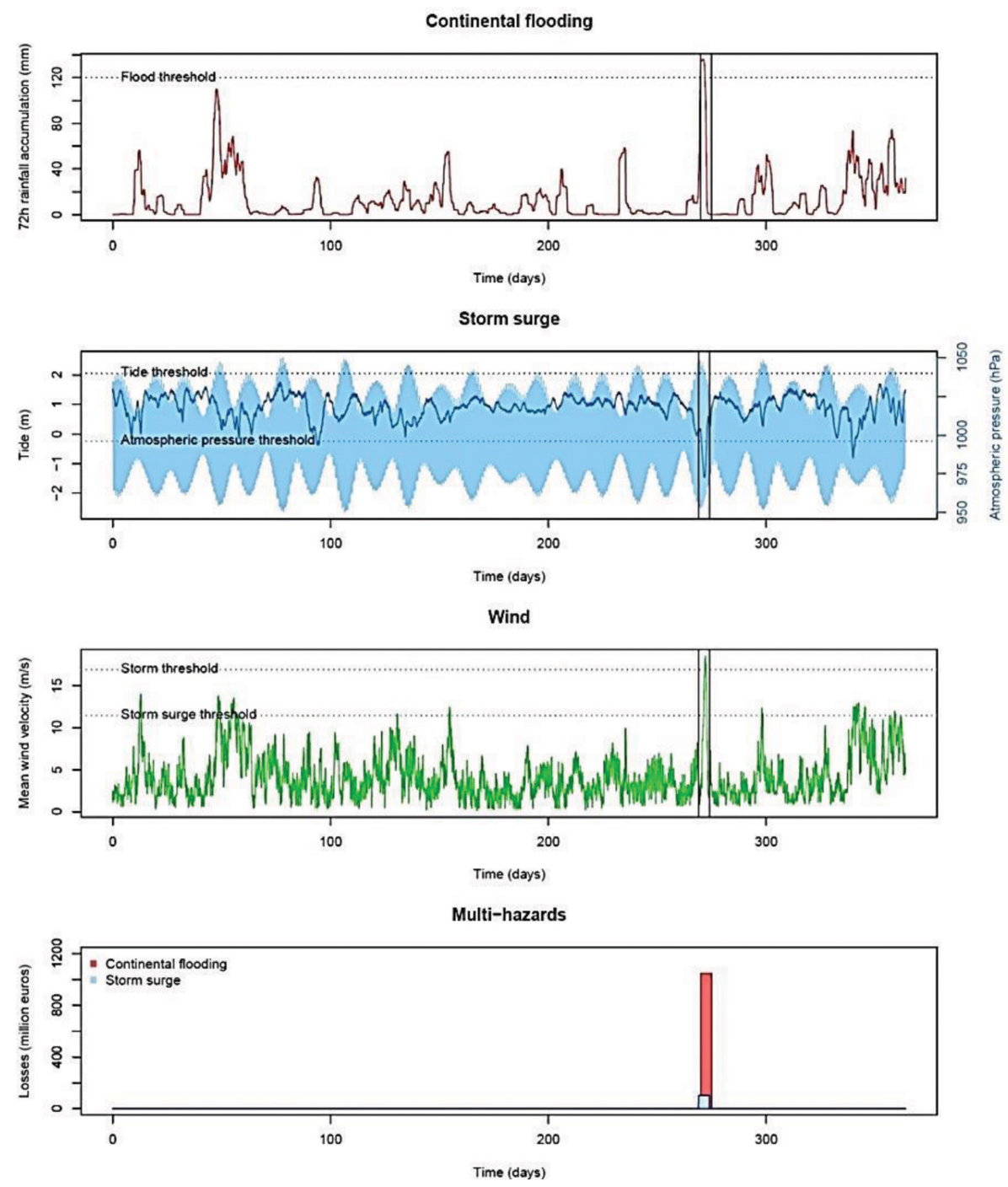

Figure 1: Representation of the event selections for the fictive year 2003.

line of business and geolocalization. Damage functions, calibrated on the historical events are used to compute the damage probability and destruction rates for the insurance portfolios. The results of the damage model are available at tree levels: communal, regional (French département) and global.

\subsection{Event detection}

Figure 1 illustrates the multi-peril detection method for a given fictive year. The climatic data provided by Météo-France are continuous data in terms of temporal and geographic extent. Among these data, the detection of Nat Cat events has to be computed. Nat Cat events are defined for flood and storm surge when hazard parameters exceed a given threshold. 


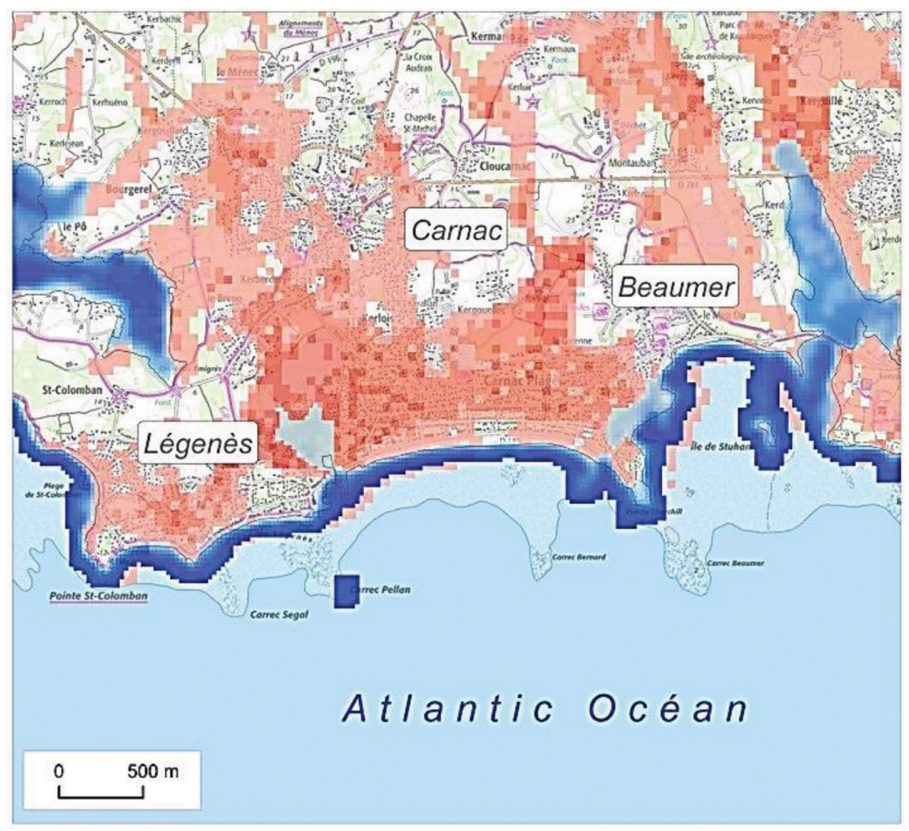

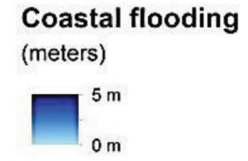

Runoff

Discharge $(\mathrm{m} 3 / \mathrm{s})$

0
60
125

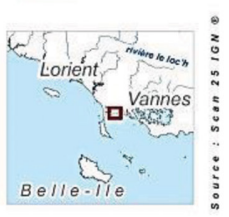

Figure 2: Storm surge and flooding hazard simulated for the 2003 fictive event in the sector of Carnac.

Flood was modelled at two different catchment scales: small watershed and large watershed, respectively, for $72 \mathrm{~h}$ rainfall events and 10-days rainfall events. Two independent flood events distributions have been built by comparing the 72 -h or $10-\mathrm{d}$ cumulative rainfall to the 10-years return period threshold.

For coastal floods, to detect the events among the continuous climatic simulations, three thresholds have been chosen for each of the 20 tide gauge stations available. The first one corresponds to the 97th percentile over the tide predicted by the OTPS model (OSU Tidal Prediction Software [15]), the second to the 1st percentile over atmospheric pressure and the third is the 99.5th percentile over wind speed. These thresholds were calibrated with a database of historical events that happened over France during the 20th Century.

The hazard of one fictive event that occurred in 2003 (at climate 2050) for flood and storm surge is illustrated in Fig. 2. This event affects all the west part of France and caused very important losses: more than one billion for continental flooding and 100 million for coastal flooding.

\subsection{Vulnerability assessment for 2050}

The evolution of vulnerability could widely influence the damages of meteorological events in 2050. Indeed, the number of exposed properties that may be affected by a natural event will increase, according to the population growth and territorial dynamics.

On the basis of INSEE (Institut National de la Statistique et des Etudes Economiques) projections for France, the number of insured properties by 2050 has been estimated at the commune level. The result is an increase in the number of risks from nearly 51 million in 2015 to almost 57 million in $2050(+11.7 \%)$. A projection of insured property values was also 


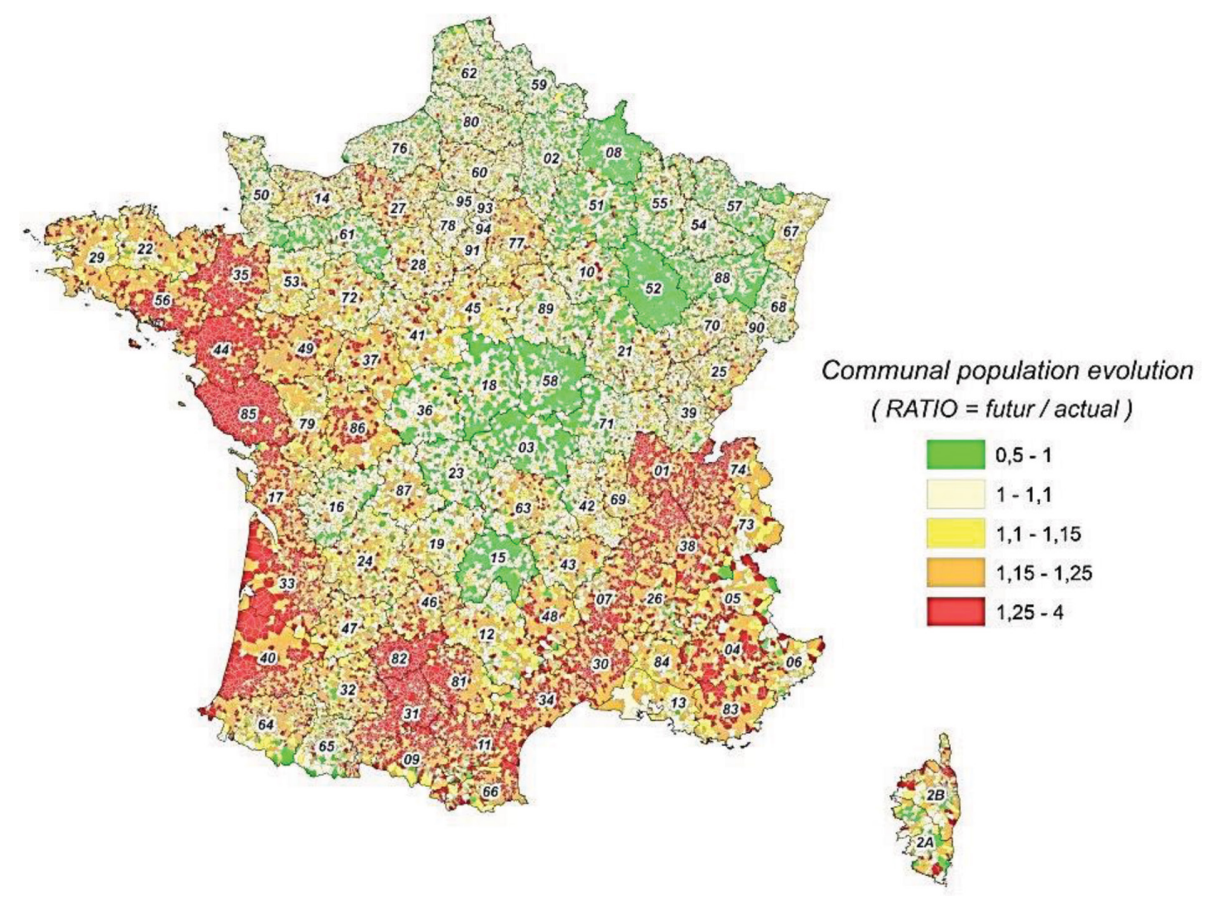

Figure 3: Map of the variation in insured values by municipality between 2015 and 2050.

produced on the basis of CCR historical insurance database over the past 10 years. According to these estimations, insured values would grow by $72 \%$ between 2015 and 2050. The map of these variations shows major regional disparities (Fig. 3) which correspond to an extrapolation of the dynamics observed today.

\section{RESULTS}

\subsection{Hazard}

By compiling the hazard maps for each event in the event sets, a probabilistic hazard map was build-up where each pixel indicates the return period of flooding. Figure $4 \mathrm{a}$ shows an extension of areas exposed to runoff between current and future climate conditions and for a same return period. For storm surge, with no significant trend on climatic effect, the most visible effect is due to the predicted rise in sea level. In areas of low relief (Fig. 4b) a $20 \mathrm{~cm}$ increase in the level of water leads to a significant extension of flooded areas for a same return period.

Several important factors have not been taken into account. Whereas the vulnerability rise was taken into account for damage calculation, its consequences such as soil sealing and diminution of natural areas that play a role of water storage are not taken into account in hazard modelling. On the other hand, all prevention and protection measures that will probably take place between now and 2050, in response to changes in the climate situation, such as dike or dam constructions are also ignored in the model. Furthermore, erosion and accretion could also significantly change the morphology of coastline in 35 years. All these aspects are very difficult to be estimated and are not considered in this study. 

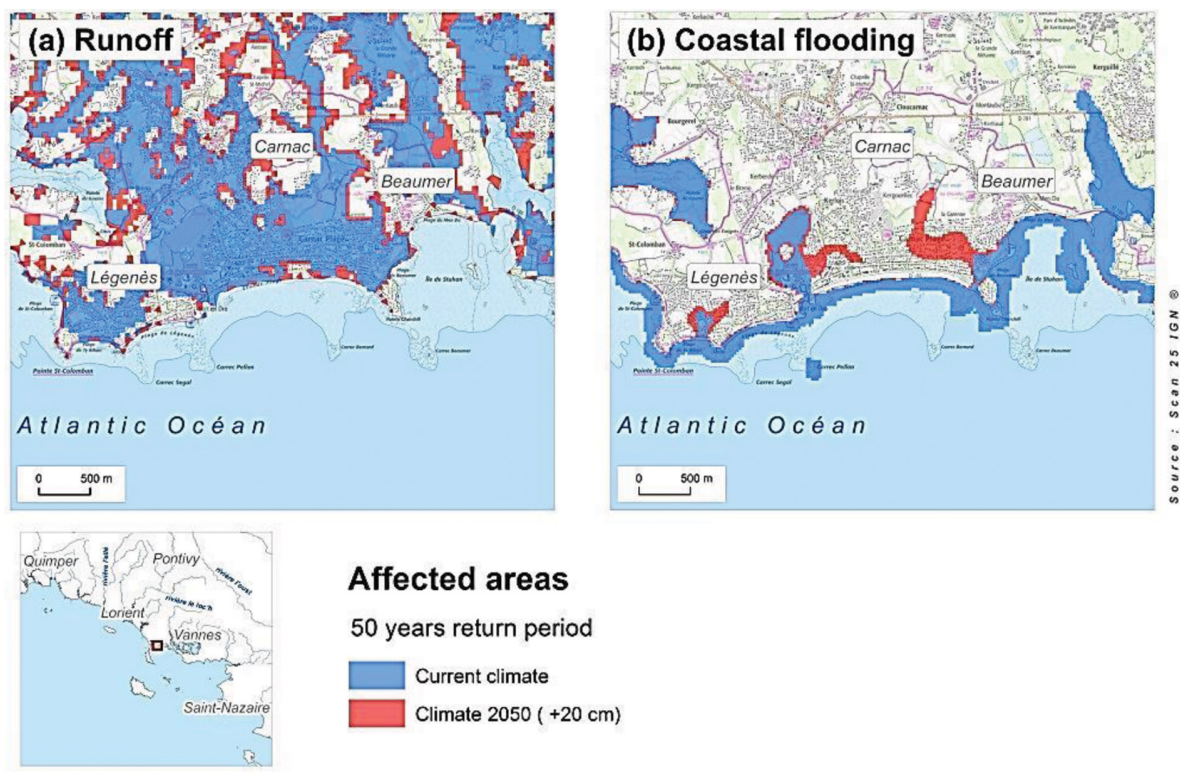

Figure 4: Variation in distribution of areas exposed to runoff (left) and storm surge (right) for a return period of 50 years between 2015 and 2050.
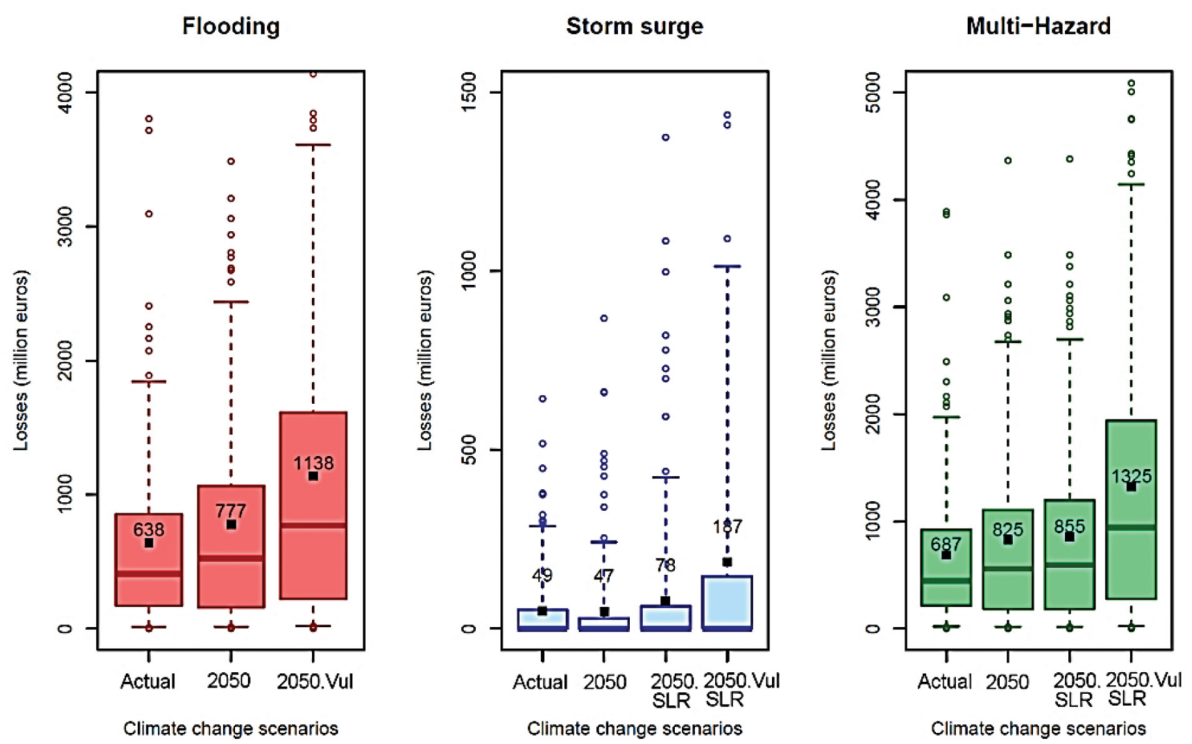

*Vul : Vulnerability, SLR : Sea level rise

Figure 5: Variation of mean annual insurance losses according to meteorological and vulnerability conditions. 


\subsection{Losses}

The distribution of event losses computed for flood and storm surge is presented in Fig. 5. For floods, these results show an increase of damages $(+20 \%)$ between current and 2050 climates. This increase is linked to the global increase of precipitations that are forecasted for 2050 climate in France by the Météo-France simulations. The insurance portfolio projections for 2050 also induce a very significant increase in the mean cost of events, for all perils. This tendency is directly correlated with the demographic evolution.

In terms of climatic variation alone, the results presented in Fig. 5 do not show clear trends towards an increase in the intensity and frequency of coastal flooding by 2050 . Indeed, the mean annual loss with unchanged vulnerability is stable between 2015 and 2050. At the same time, the most extreme years (with a return period greater than 30 years) would generate significant higher losses.

The impact of a $20 \mathrm{~cm}$ sea level rise on damages is significant for storm surge. However, the greatest trend in terms of estimated costs in 2050 is due to the variation of vulnerability. In effect, according to the INSEE projections, the regions where the population increase projections are the most important are the southern and coastal regions of France, as shown in Fig. 3. These trends have a direct impact on the coastal flood losses simulated for 2050. But here again, one can suppose that the vulnerability will have to adapt to changes in sea level. Multi-hazard results show that the weight of coastal flood damages could rise from $7 \%$ to $14 \%$ of total damages from now to 2050 .

\section{CONCLUSIONS}

The aim of this work was to simulate at current and future conditions the insured losses due to climatic disasters. The choice of the RCP 4.5 was a bit above the objectives targeted during COP 21 in Paris, which was to limit the temperature rise to $2^{\circ} \mathrm{C}$ in 2100 .

Continental and coastal flood hazard and damages were simulated at an infra-communal scale. The annual amount of damages generated by both flood and storm surge will rise from 855 to $1325 \mathrm{M} €(\sim+55 \%)$, following the rise of insured good values (population growth and insured value rise). The increase of precipitations (for flood) or the rise of sea level (for storm surge) will play a smaller part $(20 \%)$ in the global increase.

These conclusions are strongly impacted by the choice of the RCP 4.5 scenario, driven by the COP 21 perspectives. In order to assess the impact of a more pessimistic projection for the future, the RCP 6.0 will be simulated in the next phase of the project. Furthermore, 400 years of climatic simulations will be used to enforce the estimations of the annual mean losses.

\section{REFERENCES}

[1] Munich Re, El Niño curbs losses from natural catastrophes in 2015, 2016, available at http://www.munichre.com/site/corporate/get/params_E-1114418351_Dattachment/ 1130649/2016-01-04-natcat-2015-en.pdf

[2] SIGMA, Catastrophes naturelles et techniques en 2015, Swiss Re: Zurich, p. 44, 2016.

[3] IPCC, Summary for policymakers. In Climate Change 2013: The Physical Science Basis. Contribution of Working Group I to the Fifth Assessment Report of the Intergovernmental Panel on Climate Change, eds. T.F.Stocker, D. Qin, G.-K. Plattner, M. Tignor, S.K. Allen, J. Boschung, A. Nauels, Y. Xia, V. Bex \& P.M. Midgley, Cambridge University Press: Cambridge, United Kingdom and New York, NY, USA, 2013. 
[4] Christensen, J.H. \& Christensen, O.B., Climate modelling: Severe summertime flooding in Europe. Nature, 421(6925), pp. 805-806, 2003.

http://dx.doi.org/10.1038/421805a

[5] Bates, B.C., Kundzewics, Z.W., Wu, S. \& Palutikof, J.-P., Climate change and water. Technical paper of the Intergovernmental Panel on Climate Change, IPCC secretariat: Geneva, 210, 2008.

[6] Hallegatte, S., Ranger, N., Mestre, O., Dumas, P., Corfee-Morlot, J., Herweijer, C. \& Wood, R.M., Assessing climate change impacts, sea level rise and storm surge risk in port cities: a case study on Copenhagen. Climatic Change, 104, pp. 113-137, 2011. http://dx.doi.org/10.1007/s10584-010-9978-3

[7] Moncoulon, D., Labat, D., Ardon, J., Leblois, E., Onfroy, T., Poulard, C., Aji, S., Rémy, A. \& Quantin, A., Analysis of the French insurance market exposure to floods: a stochastic model combining river overflow and surface runoff. Natural Hazards and Earth System Science, 14, pp. 2469-2485, 2014.

http://dx.doi.org/10.5194/nhess-14-2469-2014

[8] Naulin, J.P., Moncoulon, D., Le Roy, S., Pedreros, R., Idier, D. \& Oliveros, C., Estimation of insurance-related losses resulting from coastal flooding in France. Natural Hazards and Earth System Science, 16, p. 13, 2016.

http://dx.doi.org/10.5194/nhess-16-195-2016

[9] Déqué, M., Dreveton, C., Braun, A. \& Cariolle, D., The ARPEGE-IFS atmosphere model: A contribution to the French community climate modelling. Climate Dynamics, 10, pp. 249-266, 1994.

http://dx.doi.org/10.1007/BF00208992

[10] Voldoire, A., Sanchez-Gomez, E., Salas y Malia, D., Decharme, B., Cassou, C., Senesi, S., Valcke, S., Beau, I., Alias, M., Deque, M., Deshayes, J., Douville, H., Fernandez, E., Madec, G., Maisonnave, E., Moine, M.-P., Planton, S., Saint-Martin, D., Szopa, S., Tyteca, S., Alkama, R., Belamari, S., Braun, A., Coquart, L. \& Chauvin, F., The CNRMCM5.1 global climate model: description and basic evaluation. Climate Dynamics, 40(9), pp. 2091-2121, 2012, http://dx.doi.org/10.1007/s00382-011-1259-y

[11] Le Moigne, P., Boone, A., Belamari, S., Brun, E., Calvet, J.-C, Decharme, B., Faroux, S., Gibelin, A.-L., Giordani, H., Lafont, S., Lebeaupin, C., Le Moigne, P., Mahfouf, J.-F., Martin, E., Masson, V., Mironov, D., Morin, S., Noilhan, J., Tulet, P., Van Den Hurk, B. \& Vionnet, V., SURFEX scientific documentation, available at http://www. cnrm.meteo.fr/surfex/IMG/pdf/surfex_scidoc_v2.pdf, 2012.

[12] Hervouet, J.-M. \& Van Haren, L., TELEMAC2D Version 3.0 Principle Note (No. Rapport EDF HE-4394052B), Electricité de France. Chatou Cedex: Département Laboratoire National d'Hydraulique, 1996.

[13] Guillou, N. \& Chapalain, G., Modeling the tide-induced modulation of wave height in the outer Seine estuary. Journal of Coastal Research, 28(3), pp. 613-623, 2012. http://dx.doi.org/10.2112/JCOASTRES-D-11-00075.1

[14] Horritt, M.S. \& Bates, P.D., Predicting floodplain inundation: raster-based modelling versus the finite-element approach. Hydrological Processes, 15, pp. 825-842, 2001. http://dx.doi.org/10.1002/hyp.188

[15] Egbert, G.D., Bennett, A.F. \& Foreman, M.G.G., TOPEX/POSEIDON tides estimated using a global inverse model. Journal of Geophysical Research, 99, 1994.

http://dx.doi.org/10.1029/94jc01894 